\title{
Long-term disease and neurological outcomes in patients with pediatric intramedullary spinal cord tumors
}

\author{
Clinical article
}

\author{
Raheel Ahmed, M.D., Ph.D., ${ }^{1}$ Arnold H. Menezes, M.D., ${ }^{1}$ Olatilewa O. Awe, M.D., ${ }^{1}$ \\ and James C. Torner, Ph.D. ${ }^{2}$ \\ Departments of ${ }^{1}$ Neurosurgery and ${ }^{2}$ Epidemiology, University of Iowa Hospitals and Clinics, Iowa City, Iowa
}

\begin{abstract}
Object. Radical resection is recommended as the first-line treatment for pediatric intramedullary spinal cord tumors (IMSCTs), but it is associated with morbidity, including risk of neurological decline and development of postoperative spinal deformity. The authors report long-term data on clinical and treatment determinants affecting disease survival and neurological outcomes.

Methods. Case records for pediatric patients ( $<21$ years of age at presentation) who underwent surgery for IMSCTs at the authors' institution between January 1975 and January 2010 were analyzed. The patients' demographic and clinical characteristics (including baseline neurological condition), the treatment they received, and their disease course were reviewed. Long-term disease survival and functional outcome measures were analyzed.

Results. A total of 55 patients (30 male and 25 female) were identified. The mean duration of follow-up ( \pm SEM) was $11.4 \pm 1.3$ years (median 9.3 years, range $0.2-37.2$ years). Astrocytomas were the most common tumor subtype (29 tumors [53\%]). Gross-total resection (GTR) was achieved in 21 (38\%) of the 55 patients. At the most recent follow-up, 30 patients (55\%) showed neurological improvement, 17 (31\%) showed neurological decline, and $8(15 \%)$ remained neurologically stable. Patients presenting with McCormick Grade I were more likely to show functional improvement by final follow-up $(\mathrm{p}=0.01)$ than patients who presented with Grades II-V. Kaplan-Meier actuarial tumor progression-free survival rates at 5, 10, and 20 years were $61 \%, 54 \%$, and $44 \%$, respectively; the overall survival rates were $85 \%$ at 5 years, $74 \%$ at 10 years, and $64 \%$ at 20 years. On multivariate analysis, GTR $(\mathrm{p}=0.04)$ and tumor histological grade $(\mathrm{p}=0.02)$ were predictive of long-term survival; GTR was also associated with improved 5-year progression-free survival $(\mathrm{p}=0.01)$.

Conclusions. The prognosis for pediatric IMSCTs is favorable with sustained functional improvement expected in a significant proportion of patients on long-term follow-up. Long-term survival at 10 years (75\%) and 20 years $(64 \%)$ is associated with aggressive resection. Gross-total resection was also associated with improved 5-year progression-free survival $(86 \%)$. Hence, the treatment benefits of GTR are sustained on extended follow-up. (http://thejns.org/doi/abs/10.3171/2014.1.PEDS13316)
\end{abstract}

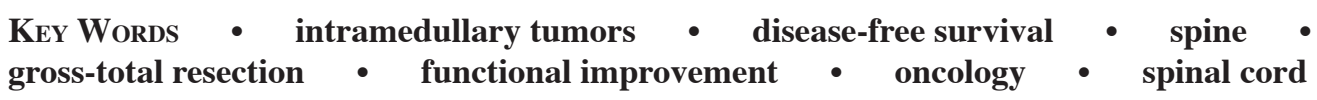

$\mathrm{T}$ HE primary treatment goal for pediatric intramedullary spinal cord tumors (IMSCTs) is to optimize tumor control through gross-total resection (GTR) when feasible, often with adjunct chemotherapy and radiation therapy. Advancements in surgical techniques and intraoperative neurological monitoring methods have enabled improvements in resection, neurological out-

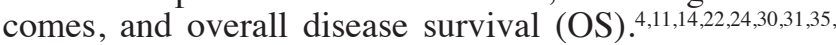
40,52 However, resection is associated with risks of neurological decline and development of secondary skeletal deformity. ${ }^{4,5,21,42}$ Additionally, within the pediatric popu-

Abbreviations used in this paper: GTR = gross-total resection; $\mathrm{HR}=$ hazard ratio; IMSCT $=$ intramedullary spinal cord tumor; OS $=$ overall (disease) survival; $\mathrm{PFS}=$ progression-free survival; $\mathrm{STR}$ $=$ subtotal resection. lation, chemotherapy and radiation therapy may produce long-term adverse effects given the growth potential of the developing nervous system..$^{27,36}$ Long-term disease outcomes are further influenced by factors such as tumor grade, tumor histology, and neurological disability at presentation..$^{5,7,14,15,19,21,38,42,50}$ Hence, establishing the longterm natural history of primary disease and prognosis of clinical treatments is critical for guiding management choices and for determining whether treatment benefits are sustained in the long run.

In this article, the first of a 2-part series, we aim to identify clinical and treatment factors that assist in prediction of long-term disease and neurological outcomes. In contrast to previous reports, extended longitudinal follow-up of our study population enabled us to assess longterm disease outcomes beyond the 1 st decade. . $^{4,18,23,30,31,38,51}$ 


\section{Long-term outcomes in pediatric intramedullary tumors}

The second article of the series addresses the long-term incidence and risk factors for development of spinal deformity in the same patient population. ${ }^{1}$

\section{Methods}

Patients with a histopathological diagnosis of intramedullary tumor in the pediatric age group $(<21$ years at presentation) were identified through a retrospective search of the neurosurgery inpatient database at the University of Iowa Hospitals and Clinics for the time period from January 1975 to January 2010. Patient records were reviewed for: 1) patient demographic characteristics, 2) clinical presentation, 3) surgical treatment, 4) chemotherapy and/or radiation therapy received, and 5) final clinical outcomes (based on clinical and radiographic evaluation by the Neurosurgery, Pediatric Oncology, and Pediatric Orthopedic Services). The senior author (A.H.M.) was the primary surgeon for most of the patients.

Preoperative and postoperative functional assessment was performed using the modified McCormick functional scale, ${ }^{29,31}$ with grades defined as follows: Grade I, neurologically intact with normal gait with or without mild focal deficit; Grade II, independent ambulation and functioning in presence of sensorimotor deficit with mild to moderate gait difficulty; Grade III, independent with external aid with moderate neurological deficit; Grade IV, functional dependence with severe moderate to severe deficits; and Grade V, paraplegic or quadriplegic requiring wheelchair with upper-extremity impairment. Imaging characteristics of the tumor were determined through preoperative CT myelography (when applicable) and MRI. Baseline and follow-up radiographic assessment of skeletal deformity was undertaken in consultation with the Pediatric Orthopedic Service.

\section{Operative Technique}

An osteoplastic laminoplasty was planned in all children unless preoperative imaging studies indicated significant mass effect that necessitated extensive decompression, often with the aid of a fascial graft, or in instances when preoperative imaging studies indicated a high probability of incomplete resection given a lack of clearly defined tumor margins. Neurophysiological monitoring with somatosensory evoked potentials was used in the last 3 decades; motor evoked potentials were adjuncts used in the last decade.

Intraoperative ultrasonography was used to identify the tumor and any accompanying syrinx cavities. A midline myelotomy was performed, spanning the levels involved by tumor. Initial biopsies were obtained from the areas that showed the most enhancement on preoperative MR imaging. Tumor debulking was initiated at the caudal end of the tumor, usually within the syrinx cavity. This was aided by high-powered microscopy and microsurgical technique with suction, ultrasonic aspiration, and cottonoid patty wisps soaked with thrombin. Bipolar cautery was infrequently needed. Circumferential dissection was extended in all planes where a distinct tumor-spinal cord interface could be identified. The mean arterial pressure was monitored carefully and maintained above $70 \mathrm{~mm}$
$\mathrm{Hg}$ (this is critical), with vasopressor support as needed. In our opinion, laminoplasty is advantageous in aiding future instrumentation if needed, improving wound healing, and preventing CSF leaks.

Surgical records were reviewed to determine surgical approach, degree of resection, and additional intraoperative surgical findings. Degree of resection was determined through intraoperative assessment of tumor removal and verified by means of MR images obtained 1-3 days after surgery. Tumor resection was classified as GTR if the surgeon's and radiographic assessment were in agreement. In all other cases, subtotal resection (STR) was determined to have occurred. If laminectomy was performed at C-7 or $\mathrm{T}-1$, the cervicothoracic junction was considered to be involved. If it was performed at T-12 or L-1, the thoracolumbar junction was considered to be involved. The score for deficit on presentation was calculated based on the presence or absence of motor, sensory, bladder, or bowel deficits, with the presence of each deficit counting for 1 point, such that the scores could range from 0 (no deficits) to 4 (deficits in each category).

Patients were also followed up in consultation with the Pediatric Oncology and Radiation Oncology Services to determine whether adjunctive therapy should be administered. The University of Iowa Human Subjects Office Institutional Review Board approved this retrospective study.

\section{Statistical Analysis}

Descriptive data were presented as proportions and means with standard error of means (mean \pm SEM). Univariate analysis for all outcomes analysis was performed using the Pearson chi-square test and logistic regression. Statistical significance for both uni- and multivariate analyses was set at $p<0.05$. Progression-free survival (PFS) and OS (defined as disease survival) rates were estimated by Kaplan-Meier survival estimates and $95 \%$ confidence intervals. Multivariate analysis of survival was done by means of survival regression using the underlying Weibull distribution. Goodness of fit was assessed by means of survival graphs, log-survival plots, and Schoenfeld residual plots to assess proportionality. Variables with univariate $\mathrm{p}$ values $<0.1$ were then entered into a survival regression model for multivariate analysis. The survival assumption was verified. Input variables that had $\mathrm{p}$ values $<0.05$ after this analysis were reported as being statistically significant on multivariate analysis. All statistical analysis was performed using SAS software version 9.3 .

\section{Results}

\section{Clinical Demographics}

A total of 55 patients (30 male and 25 female) were identified who were treated during the study period (January 1975 to January 2010) (Table 1). Forty-seven patients $(85 \%)$ presented to our service for primary treatment, and 8 patients $(15 \%)$ had a history of prior surgical treatment. Magnetic resonance imaging was available for imaging on initial presentation for 44 patients (80\%); CT myelog- 
TABLE 1: Clinical and demographic characteristics of the study population*

\begin{tabular}{|c|c|}
\hline Characteristic & Value \\
\hline \multicolumn{2}{|l|}{ age in yrs } \\
\hline mean \pm SEM & $10 \pm 1$ \\
\hline range & $0.5-21$ \\
\hline \multicolumn{2}{|l|}{ sex } \\
\hline male & $30(55)$ \\
\hline female & $25(45)$ \\
\hline \multicolumn{2}{|l|}{ clinical presentation } \\
\hline \multicolumn{2}{|c|}{ time from symptom onset in mos } \\
\hline mean \pm SEM & $7.4 \pm 1.5$ \\
\hline range & $0.1-60$ \\
\hline pain & $29(52)$ \\
\hline motor deficit & $33(60)$ \\
\hline sensory deficit & $42(76)$ \\
\hline bladder deficit & $21(38)$ \\
\hline bowel deficit & $10(18)$ \\
\hline \multicolumn{2}{|l|}{ imaging findings $†$} \\
\hline syrinx & $16(36)$ \\
\hline contrast enhancement & $40(91)$ \\
\hline \multicolumn{2}{|l|}{ margins } \\
\hline diffuse & $29(66)$ \\
\hline circumscribed & $15(34)$ \\
\hline \multicolumn{2}{|c|}{ no. of vertebral levels involved } \\
\hline mean \pm SEM & $4 \pm 1$ \\
\hline range & $1-11$ \\
\hline \multicolumn{2}{|l|}{ spinal level } \\
\hline cervicomedullary & $20(36)$ \\
\hline cervicothoracic $\ddagger$ & $7(13)$ \\
\hline thoracic & $15(27)$ \\
\hline thoracolumbar§ & $8(15)$ \\
\hline lumbar & $5(9)$ \\
\hline \multicolumn{2}{|l|}{ histological diagnosis } \\
\hline astrocytoma & $29(53)$ \\
\hline Grade II & $22(40)$ \\
\hline Grade III & $6(11)$ \\
\hline Grade IV & $1(2)$ \\
\hline ependymoma & $12(22)$ \\
\hline Grade II & $8(15)$ \\
\hline Grade III & $4(7)$ \\
\hline ganglioglioma & $7(13)$ \\
\hline hemangioblastoma & $3(5)$ \\
\hline others (PNET) & $4(7)$ \\
\hline \multicolumn{2}{|l|}{ histological grade } \\
\hline low & $43(78)$ \\
\hline high (III-IV) & $12(22)$ \\
\hline
\end{tabular}

(continued)
TABLE 1: Clinical and demographic characteristics of the study population* (continued)

\begin{tabular}{lc}
\hline Characteristic & Value \\
\hline duration of FU in yrs & \\
mean \pm SEM & $11.4 \pm 1.3$ \\
range & $0.2-37.2$ \\
\hline
\end{tabular}

* Values represent numbers of cases (\%) unless otherwise indicated. $\mathrm{FU}=$ follow-up; PNET = primitive neuroectodermal tumor.

$\dagger \mathrm{MRI}$ studies were unavailable in 11 patients. Thus, the percentage values for this category were calculated using a denominator of 44 . $\ddagger$ Cervicothoracic: if tumor located within the cervical or thoracic region extended to or involved the C7-T1 levels.

$\S$ Thoracolumbar: if tumor located within the thoracic or lumbar region extended to or involved the T11-L1 levels.

raphy was used for diagnostic imaging in the remaining 11 patients (20\%).

Sensory deficits were the most common presenting symptom (present in 42 cases [76\%]). The cervicomedullary junction was the most common tumor site (being the site in 20 cases [36\%]). Astrocytomas comprised the most common tumor histological subtype (29 tumors [53\%]), followed by ependymomas (12 tumors [22\%]). Overall, low-grade tumors predominated (43 tumors [78\%]) within the study population. In $40(91 \%)$ of the 44 cases in which MRI was used for initial imaging, the tumors showed contrast enhancement. The tumor margins were well defined radiologically in 15 (34\%) of these cases; in the remaining 29 cases $(66 \%)$, the tumors had diffuse, illdefined borders on preoperative imaging.

\section{Surgical Treatment}

Surgery resulted in GTR in 21 patients $(38 \%)$ and STR in the remaining 34 patients (62\%) (Table 2). The overall incidence of surgical complications was 5\% (3 cases: wound infection in 2 cases and delayed wound healing in 1 case). There were no intra- or postoperative deaths related to surgical intervention. In all, 12 patients (22\%) developed hydrocephalus requiring ventriculoperitoneal shunt placement (in 9 cases) or significant syringomyelia that necessitated syrinx-subarachnoid shunt insertion (in 3).

\section{Postoperative Neurological Status}

Within the immediate postoperative period, the overall incidence of new-onset neurological deficit or progression of preexisting neurological deficit was $27 \%$ (15 cases) (Table 2). Progression of underlying motor deficit or development of new-onset motor symptoms occurred in 11 patients $(20 \%)$. Of these 11 patients, $7(63 \%)$ demonstrated neurological improvement during the follow-up period (median time from surgery to neurological improvement: 3 months). Underlying disease progression led to continued motor decline in 3 (27\%) of these patients. Similarly, new-onset or progressive sensory deficits were encountered in 8 patients $(14.5 \%)$ within the postoperative period. Neurological recovery was noted in $4(50 \%)$ of these 
TABLE 2: Clinical treatment and outcomes on long-term follow-up*

\begin{tabular}{|c|c|}
\hline Variable & Value \\
\hline \multicolumn{2}{|l|}{ surgery } \\
\hline \multicolumn{2}{|l|}{ no. of tumor surgeries } \\
\hline 1 & $39(71)$ \\
\hline 2 & $11(20)$ \\
\hline $3-4$ & $5(9)$ \\
\hline laminectomy & $41(75)$ \\
\hline mean no. of levels & 5 \\
\hline range of no. of levels & $1-11$ \\
\hline laminoplasty & $14(25)$ \\
\hline mean no. of levels & 5 \\
\hline range of no. of levels & $3-6$ \\
\hline \multicolumn{2}{|l|}{ extent of resection } \\
\hline GTR & $21(38)$ \\
\hline STR & $34(62)$ \\
\hline complications & $3(5)$ \\
\hline shunt placement & $12(22)$ \\
\hline recurrence or progression & $26(47)$ \\
\hline \multicolumn{2}{|l|}{ time to recurrence or progression in yrs } \\
\hline mean \pm SEM & $3.3 \pm 1$ \\
\hline range & $0.1-20$ \\
\hline \multicolumn{2}{|l|}{ treatment of recurrence } \\
\hline surgery & $9(16)$ \\
\hline chemo & $16(29)$ \\
\hline RT & $28(51)$ \\
\hline observation & $10(18)$ \\
\hline \multicolumn{2}{|l|}{ PFS $†$} \\
\hline 5 yrs & 61 \\
\hline 10 yrs & 54 \\
\hline 20 yrs & 44 \\
\hline \multicolumn{2}{|l|}{ ost } \\
\hline $5 \mathrm{yrs}$ & 85 \\
\hline 10 yrs & 74 \\
\hline $20 \mathrm{yrs}$ & 64 \\
\hline
\end{tabular}

* Values represent numbers of cases (\%) unless otherwise indicated. chemo = chemotherapy; $\mathrm{RT}$ = radiotherapy.

$\dagger$ The values shown are means of Kaplan-Meier product limit estimates. See text for confidence intervals.

8 (median 7 months postoperatively). The remaining patients showed disease progression with continued decline in overall neurological function. The incidence of newonset bowel or bladder dysfunction was 1.8\% (1 case) and the incidence of progression in preexisting bowel or bladder deficit was $5.5 \%$ (3 cases), respectively.

\section{Long-Term Neurological Outcomes}

The mean time to neurological improvement $( \pm$ SEM) was $4.4 \pm 0.8$ months (median 2.5 months, range 1.0-24 months). Postoperative neurological improvement was noted in 23 (70\%) of the 33 patients with initial motor deficits, 27 (64\%) of the 42 with sensory deficits, 4 (19\%) of the 21 with bladder deficits, and $4(40 \%)$ of the 10 with bowel deficits on presentation.

The mean duration of follow-up $( \pm$ SEM) was $11.4 \pm$ 1.3 years (median 9.3 years, range $0.2-37.2$ years). By final follow-up, 30 patients (55\%) showed neurological improvement and 17 (31\%) showed neurological decline, while 8 $(15 \%)$ remained neurologically stable (Table 3 ). Of patients who showed postoperative neurological improvement, the median duration of time from surgery until symptom improvement was $4 \pm 1$ months (range $0-24$ months). Patients who presented with McCormick Grade I were more likely to show functional improvement by final follow-up ( $\mathrm{p}=$ 0.01 , Fisher's test), as compared with patients who presented with Grades II-V. Conversely, patients who presented with McCormick Grades I and II were more likely to show functional improvement or remain stable by final followup ( $p=0.04$, Fisher exact test) than patients who presented with Grades III-V. Motor deficits were most likely to show improvement on long-term follow-up (with improvement seen in 23 [70\%] of 33 cases), followed by sensory deficits (with improvement seen in 27 [64\%] of 42 cases) (Table 4).

\section{Adjunct Therapy}

Chemotherapy was used in 16 patients (29\%). It was used as adjuvant therapy in 11 patients (20\%) and for treatment of tumor recurrence or progression in $5(9 \%)$. Radiotherapy was used in 28 patients (51\%) - as adjuvant therapy in 23 patients $(42 \%)$ and for treatment of tumor recurrence or progression in 5 patients (9\%).

\section{Survival and PFS Outcomes}

Disease recurrence/progression was noted in 26 patients $(47 \%)$. The mean time from the primary surgical procedure to the onset of recurrence or progression was 3 months. The Kaplan-Meier actuarial tumor PFS rates at 5,10 , and 20 years were $61 \%$ (95\% CI 46\%-72\%), 54\% (95\% CI 39\%-66\%), and 44\% (95\% CI 27\%-60\%), respectively; OS rates were $85 \%(95 \%$ CI $75 \%-95 \%)$ at 5 years, $74 \%(95 \% \mathrm{CI} 61 \%-87 \%)$ at 10 years, and $64 \%$ (95\% CI 46\%-82\%) at 20 years (Table 2 and Fig. 1).

On analyzing predictors for OS, the following variables were found to be significant on univariate analysis: tumor grade, functional grade on presentation and initial discharge, resection, shunt placement, use of chemo- and/ or radiotherapy, and number of tumor surgeries. On multivariate analysis, GTR (hazard ratio [HR] 8.83, p < 0.04), tumor grade (HR 0.24, $\mathrm{p}=0.02$ ), and number of tumor resections (HR 0.26, $\mathrm{p}=0.03$ ) were found to be predictive of long-term survival (Table 5 and Fig. 2). The 10-year OS rate was $61 \%$ (95\% CI 42\%-80\%) in patients who underwent STR as compared with 94\% (95\% CI 84\%-100\%) in patients who underwent GTR. Similarly, the 10-year OS was $82.3 \%$ (95\% CI 67\%-93\%) in patients with low-grade tumors in comparison with $51 \%$ (95\% CI $18 \%-77 \%)$ in patients with high-grade tumors. For the patients who underwent only 1 tumor resection procedure, the 10 -year OS was $87 \%$ (95\% CI 72\%-95\%) as compared with patients who underwent more than 1 resection procedure, for whom the OS was $48 \%$ (95\% CI 25\%-75\%). 
TABLE 3: Summary of functional and neurological outcomes stratified by functional grade at initial presentation*

\begin{tabular}{|c|c|c|c|c|c|c|c|c|c|}
\hline \multirow[b]{2}{*}{ Grade at Presentation } & \multirow[b]{2}{*}{ No. of Pts (\%) } & \multicolumn{5}{|c|}{ Funct'l Grade at Last FU } & \multicolumn{3}{|c|}{$\begin{array}{c}\text { Neurol Cond at Last FU } \\
\text { (no. of pts. [\%]) }\end{array}$} \\
\hline & & I & II & III & IV & V & Improved & Stable & Worse \\
\hline I & $19(34)$ & 17 & 1 & & 1 & & $12(63)$ & $6(32)$ & $1(5)$ \\
\hline$\|$ & $18(32)$ & 9 & 2 & 3 & & 4 & $10(55)$ & $1(6)$ & $7(39)$ \\
\hline III & $6(11)$ & & 3 & & & 3 & $2(34)$ & - & $4(66)$ \\
\hline IV & $6(11)$ & 1 & 2 & & 1 & 2 & $3(50)$ & - & $3(50)$ \\
\hline V & $6(11)$ & & 2 & & 1 & 3 & $3(50)$ & $1(17)$ & $2(33)$ \\
\hline
\end{tabular}

* Funct'l = functional; Neurol Cond = neurological condition; Pts = patients.

Functional grade on presentation, resection, shunt placement, use of chemo- and/or radiotherapy, and number of tumor surgeries were found to be predictive of long-term PFS on univariate analysis. Only number of tumor resections $>1(\mathrm{HR} 8.7, \mathrm{p}=0.01)$ significantly correlated with PFS on multivariate analysis (Table 6).

We also analyzed determinants of short-term (5-year) PFS. On multivariate analysis, GTR (HR 4.59, p = 0.01), use of radiation therapy (HR $0.33, \mathrm{p}=0.04$ ), and preoperative functional Grades III and IV (HR 8.37, p < 0.01) were significantly correlated with 5-year PFS. Of these 3 factors, only GTR led to improved 5-year PFS (86\% 5 -year PFS in patients who had GTR as compared with 47\% 5-year PFS in patients who had STR; multivariate $\mathrm{p}=0.04$; Kaplan-Meier analysis). Inclusion of radiation therapy was associated with lower 5-year PFS (57\% in patients who received radiation therapy as compared with $19 \%$ those who did not receive any adjuvant or delayed radiation therapy) and represents an inherent selection bias.

We found no correlation between any of the clinical or treatment factors and functional improvement by the last follow-up.

\section{Discussion}

Optimal management of pediatric IMSCTs entails careful consideration of management options, given the lifetime morbidity of neurological disease in pediatric patients. Considerations include the natural history of primary disease following resection, iatrogenic risk of neurological progression following surgery, developmental and biomechanical immaturity of the pediatric spine, and susceptibility of the developing nervous system to adjunct chemo-radiotherapy treatments. Our results provide an over-

TABLE 4: Summary of neurological deficits at initial presentation and improvement at last follow-up

\begin{tabular}{lcc}
\hline Deficit & No. of Pts w/ Deficit & $\begin{array}{c}\text { No. of Pts (\%) w/ Improvement } \\
\text { at Last FU }\end{array}$ \\
\hline motor & 33 & $23(70)$ \\
sensory & 42 & $27(64)$ \\
bladder & 21 & $4(19)$ \\
bowel & 10 & $4(40)$ \\
\hline
\end{tabular}

view of the long disease course and outcomes in pediatric patients with intramedullary tumors following treatment through direct follow-up extending beyond the 1st decade after treatment for the first time. We have further identified demographic, clinical, and treatment factors that predict neurological improvement and disease outcomes on longterm follow-up. Our results indicate that favorable (74\% at 10 years and $63 \%$ at 20 years) long-term OS rates may be observed in the pediatric population with intramedullary tumors. On multivariate analysis, extent of resection is the most significant predictor of extended long-term survival and 5-year PFS. Functional improvement was observed in approximately $50 \%$ of all patients by last follow-up and was even seen in patients initially presenting with the worst functional status (Grades IV-V).
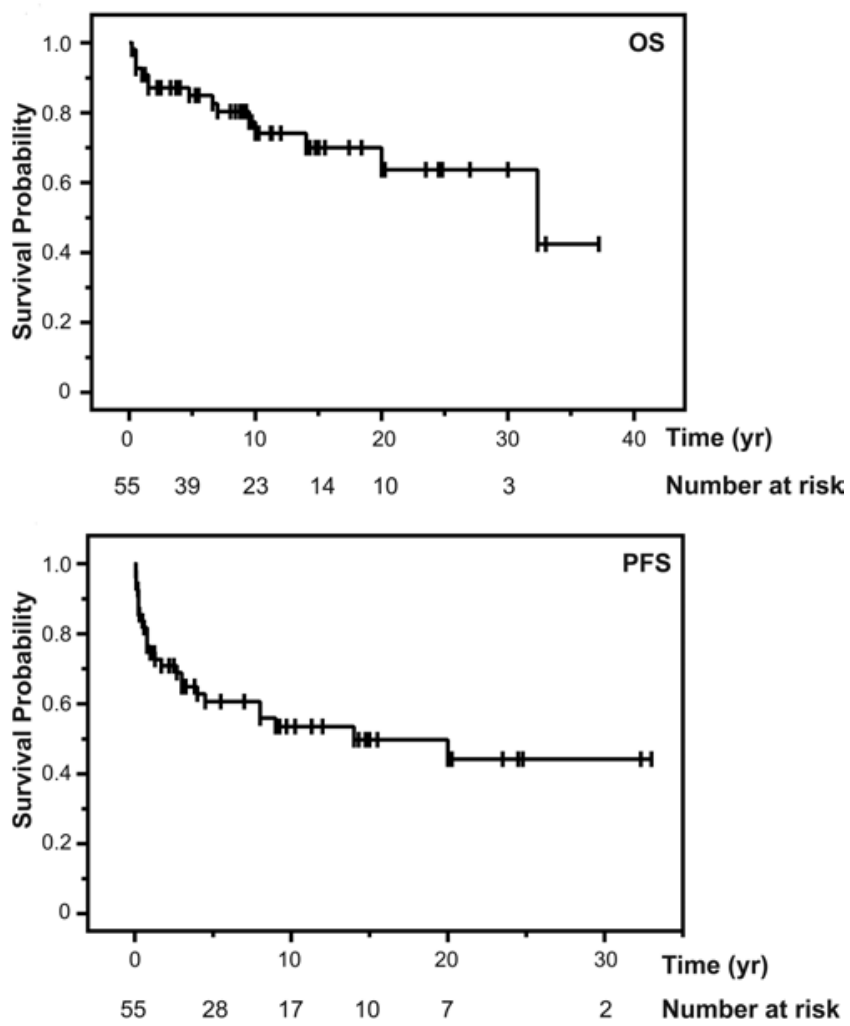

FIG. 1. Upper: Overall disease survival in study group as determined with the Kaplan-Meier method. Lower: Overall PFS in study group determined similarly. Vertical hatches indicate censored events. 
Long-term outcomes in pediatric intramedullary tumors

TABLE 5: Factors associated with overall disease survival

\begin{tabular}{|c|c|c|c|c|c|}
\hline \multirow[b]{2}{*}{ Factor } & \multirow[b]{2}{*}{ Alive (\%) } & \multirow[b]{2}{*}{ Dead (\%) } & \multirow[b]{2}{*}{ Univariate Analysis $p$ Value } & \multicolumn{2}{|c|}{ Multivariate Analysis } \\
\hline & & & & $\mathrm{HR}$ & $p$ Value \\
\hline \multicolumn{6}{|l|}{ age } \\
\hline$<5(n=20)$ & $15(75)$ & $5(25)$ & 0.0912 & & \\
\hline $6-13(n=18)$ & $10(56)$ & $8(44)$ & & & \\
\hline $14-21(n=17)$ & $15(88)$ & $2(12)$ & & & \\
\hline \multicolumn{6}{|l|}{ sex } \\
\hline male $(n=30)$ & $22(73)$ & $8(27)$ & 0.912 & & \\
\hline female $(n=25)$ & $18(72)$ & $7(28)$ & & & \\
\hline \multicolumn{5}{|l|}{ pathology } & \\
\hline astrocytoma $(\mathrm{n}=31)$ & $20(65)$ & $11(35)$ & 0.4733 & & \\
\hline ependymoma $(n=10)$ & $8(80)$ & $2(20)$ & & & \\
\hline ganglioglioma $(n=7)$ & $6(86)$ & $1(14)$ & & & \\
\hline other $(n=7)$ & $6(86)$ & $1(14)$ & & & \\
\hline \multicolumn{6}{|l|}{ grade } \\
\hline high grade $(n=43)$ & $6(50)$ & $6(50)$ & $0.0456^{*}$ & 0.24 & 0.02 \\
\hline low grade $(n=12)$ & $34(79)$ & $9(21)$ & & & \\
\hline \multicolumn{6}{|l|}{ clinical presentation } \\
\hline$\leq 2(n=39)$ & $30(77)$ & $9(23)$ & 0.2753 & & \\
\hline$>2(n=16)$ & $10(63)$ & $6(38)$ & & & \\
\hline \multicolumn{6}{|c|}{ funct'l grade on presentation } \\
\hline$I-I I(n=37)$ & $31(84)$ & $6(16)$ & $0.0163^{*}$ & & \\
\hline III $(n=6)$ & $2(33)$ & $4(67)$ & & & \\
\hline $\mathrm{IV}-\mathrm{V}(\mathrm{n}=12)$ & $7(58)$ & $5(42)$ & & & \\
\hline \multicolumn{6}{|l|}{ tumor location† } \\
\hline cervical $(n=27)$ & $20(74)$ & $7(26)$ & 0.8720 & & \\
\hline thoracic $(n=23)$ & $16(70)$ & $7(30)$ & & & \\
\hline lumbar $(n=5)$ & $4(80)$ & $1(20)$ & & & \\
\hline \multicolumn{6}{|l|}{ myelotomy levels } \\
\hline cervical $(n=24)$ & $17(71)$ & $7(29)$ & 0.9615 & & \\
\hline thoracic $(n=27)$ & $20(74)$ & $7(26)$ & & & \\
\hline lumbar $(n=4)$ & $3(75)$ & $1(25)$ & & & \\
\hline \multicolumn{6}{|l|}{ syrinx } \\
\hline yes $(n=16)$ & $14(88)$ & $2(12)$ & 0.4601 & & \\
\hline no $(n=28)$ & $22(79)$ & $6(21)$ & & & \\
\hline \multicolumn{6}{|l|}{ margins } \\
\hline circumscribed $(n=15)$ & $13(87)$ & $2(13)$ & 0.5487 & & \\
\hline diffuse $(n=29)$ & $23(79)$ & $6(21)$ & & & \\
\hline \multicolumn{6}{|l|}{ enhancement } \\
\hline yes $(n=40)$ & $32(80)$ & $8(20)$ & 0.3227 & & \\
\hline no $(n=4)$ & $4(100)$ & $0(0)$ & & & \\
\hline \multicolumn{6}{|l|}{ no. of vertebral levels involved } \\
\hline $1-2(n=13)$ & $10(77)$ & $3(23)$ & 0.0739 & & \\
\hline $3-4(n=18)$ & $14(78)$ & $4(22)$ & & & \\
\hline $5-6(n=14)$ & $12(86)$ & $2(14)$ & & & \\
\hline$>7(n=10)$ & $4(40)$ & $6(60)$ & & & \\
\hline
\end{tabular}

(continued) 
TABLE 5: Factors associated with overall disease survival (continued)

\begin{tabular}{|c|c|c|c|c|c|}
\hline \multirow[b]{2}{*}{ Factor } & \multirow[b]{2}{*}{ Alive (\%) } & \multirow[b]{2}{*}{ Dead (\%) } & \multirow[b]{2}{*}{ Univariate Analysis $p$ Value } & \multicolumn{2}{|c|}{ Multivariate Analysis } \\
\hline & & & & $\mathrm{HR}$ & p Value \\
\hline \multicolumn{6}{|l|}{ surgical treatment } \\
\hline \multicolumn{6}{|l|}{ resection } \\
\hline $\operatorname{GTR}(n=21)$ & $20(95)$ & $1(5)$ & $0.0032^{*}$ & 8.83 & 0.04 \\
\hline $\operatorname{STR}(n=34)$ & $20(59)$ & $14(41)$ & & & \\
\hline \multicolumn{6}{|l|}{ shunt placement } \\
\hline yes $(n=12)$ & $4(33)$ & $36(84)$ & $0.0005^{*}$ & & \\
\hline no $(n=43)$ & $8(67)$ & $7(16)$ & & & \\
\hline \multicolumn{6}{|l|}{ no. of tumor surgeries } \\
\hline $1(n=39)$ & $32(82)$ & $7(18)$ & $0.0153^{*}$ & 0.26 & 0.03 \\
\hline$>1(n=16)$ & $8(50)$ & $8(50)$ & & & \\
\hline \multicolumn{6}{|l|}{ funct'l status on discharge } \\
\hline$|-| \mid(n=38)$ & $31(82)$ & $7(18)$ & $0.0654^{*}$ & & \\
\hline III $(n=5)$ & $2(40)$ & $3(60)$ & & & \\
\hline IV-V (n= 12) & $7(58)$ & $5(42)$ & & & \\
\hline \multicolumn{6}{|l|}{ adjuvant therapy } \\
\hline \multicolumn{6}{|l|}{ chemo/RT used } \\
\hline chemo \& RT $(n=10)$ & $4(40)$ & $6(60)$ & $0.0005^{*}$ & & \\
\hline $\mathrm{RT}(\mathrm{n}=16)$ & $8(50)$ & $8(50)$ & & & \\
\hline chemo $(n=6)$ & $6(100)$ & $0(0)$ & & & \\
\hline none $(n=23)$ & $22(96)$ & $1(4)$ & & & \\
\hline \multicolumn{6}{|l|}{ indication for chemo } \\
\hline not used $(n=39)$ & $30(77)$ & $9(23)$ & 0.4411 & & \\
\hline adjuvant or recurrence $(n=15)$ & $10(67)$ & $5(33)$ & & & \\
\hline \multicolumn{6}{|l|}{ indication for RT } \\
\hline not used $(n=27)$ & $26(96)$ & $1(4)$ & $0.0002^{*}$ & & \\
\hline adjuvant or recurrence $(n=25)$ & $13(52)$ & $12(48)$ & & & \\
\hline
\end{tabular}

* Factors included in multivariate analysis. The following factors were used in the multivariate model based on survival regression using an underlying Weibull distribution: tumor grade, functional grade on presentation, tumor span, resection, shunt placement, functional status on discharge, use of chemotherapy and/or radiotherapy, indication for radiotherapy, and number of tumor surgeries.

† Tumor localization and span were categorized as cervical (including cervicomedullary, cervical, and cervicothoracic segments [C7-T1]), thoracic (thoracic and thoracolumbar segments [T11-L1]), and lumbar (lumbar/conus).

Although the fact that this study is a single-institution case series might be seen as a limitation, it minimizes bias due to patient selection and treatment. In contrast to previous studies, $, 4,8,23,30,51$ this study reports on disease outcomes over an extended follow-up beyond the 1st decade after surgery and thereby serves to better define the disease course and treatment outcomes for pediatric IMSCTs.

\section{Rates of Long-Term Disease Survival}

In our series, the 10 -year survival rate $(74 \%)$ is consistent with that reported by Constantini et al. and also falls within the range of previous additional studies. ${ }^{4,38,48}$ With a mean follow-up of approximately 11.5 years, we determined the 20-year disease survival rate to be $64 \%$. Our extended follow-up enabled us to determine that up to $44 \%$ of patients were free of progression 20 years posttreatment. This indicates relatively favorable disease outcomes for a potentially debilitating disease affecting children and adolescents. These long-term follow-up results therefore provide the first report of disease survival estimates beyond 1 decade posttreatment.

\section{Determinants of Long-Term Survival}

On univariate analysis, factors that significantly correlated with OS were functional status on presentation, histological grade, extent of resection, and CSF shunt placement. These factors have been observed to be predictive of OS in previous studies. Additional factors significant on univariate analysis included number of tumor surgeries and need for adjuvant therapy, which are surrogate markers for disease progression. On multivariate analysis, extent of resection, tumor histology grade, and number of tumor resection procedures were significantly predictive of long-term disease survival. 

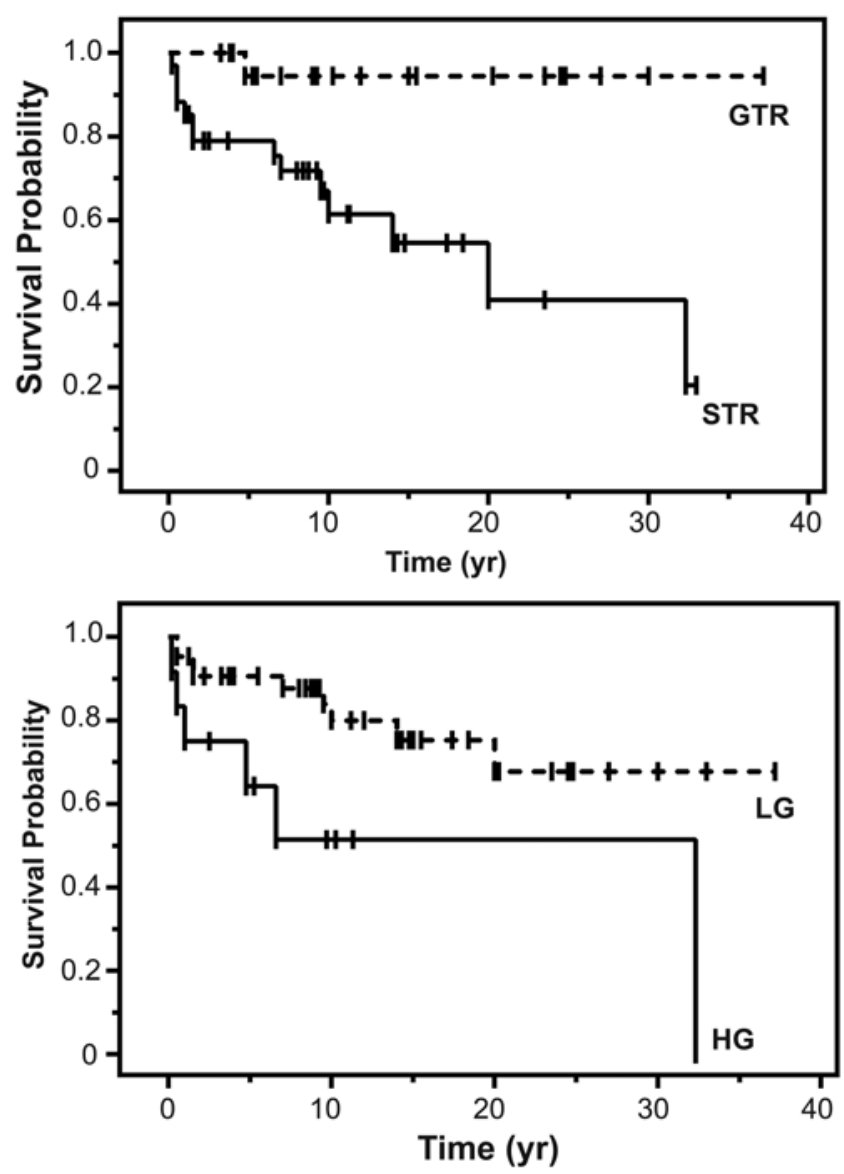

FIG. 2. Upper: Comparison of disease survival between patients who underwent GTR (dashed line) and STR (solid line). Lower: Comparison of disease survival between patients with low (LG, dashed line) and high (HG, solid line) tumor histological grades. Vertical hatches indicate censored events.

Extent of Resection. Since initially advocated, GTR remains the definitive surgical goal in the treatment of IMSCTs. ${ }^{6,11,14}$ Results from previous studies have been ambiguous on the survival predictive value of resection, with some studies indicating improved long-term survival and neurological outcomes, ${ }^{6,13}$ while others support the role for limited resections followed by adjuvant therapies. ${ }^{33,36,48}$ This discrepancy is in part attributed to the heterogeneity in surgical versus radiographic assessment of tumor resection and variability in defined surgical margins that often limits resection..$^{9,25}$ The extent of tumor resection and benefits of GTR correlate with tumor histology. ${ }^{16,20,23,45}$ Low-grade pilocytic astrocytoma subtypes are much more likely to be associated with defined tumor margins than are higher-grade astrocytomas. This may also account for variability in reported rates of GTR for astrocytomas and hence confounds the predictive association between extent of resection and disease outcomes. ${ }^{41-43}$

The overall GTR rate in our series $(38 \%)$ was lower than that previously reported by some authors ${ }^{4}$ but in line with the rate reported by others. ${ }^{44}$ In contrast to earlier studies, ${ }^{2,33}$ our results support the beneficial role for GTR, where feasible, in long-term disease survival and prevention of disease progression over extended follow-up. ${ }^{30}$
The predictive value of extent of resection was maintained across our cumulative case series. This finding is significant, since astrocytomas were the most prevalent histological subtype in our series and are frequently associated with indistinct tumor margins. Our results therefore emphasize the importance of resection in predicting long-term disease and neurological outcomes within the pediatric age group. ${ }^{11}$

In addition, extent of resection was also significantly associated with improved PFS in this study, in contrast to an earlier study that did not find an association between GTR and PFS in astrocytomas. ${ }^{16}$ Of particular note, the survival advantage of GTR was maintained at the 5-year time point in contrast to an earlier report that indicated similar results for GTR and STR in terms of PFS beyond 3 years of follow-up. ${ }^{4}$

Tumor Histology and Grade. Tumor grade was also significantly associated with disease survival outcome on multivariate analysis, in line with findings of earlier studies that describe the prognostic value of tumor grade. ${ }^{17,33}$ In contrast to earlier studies, however, we did not find any statistically significant association with histological subtype. ${ }^{4,23,33}$ Tumor margins and hence extent of resection are directly related to tumor grade and histological subtype. Hence, our finding of the prognostic value of resection extent is an indirect reflection of this underlying association. This is supported by the observation that the major tumor histological subtype/grade were low-grade astrocytomas, ependymomas, and gangliogliomas, which are typically slow-growing and indolent tumors. ${ }^{2}$

\section{Hydrocephalus and Syringomyelia}

Development of symptomatic hydrocephalus and/or syringomyelia necessitating shunt placement was a significant factor in our group on univariate analysis. The association between hydrocephalus and intramedullary tumors has been well described, both as a presenting symptom and as a manifestation of disease progression..$^{37,49}$ Obstruction of CFS occurs through leptomeningeal disease in patients with high-grade tumors and secondary to altered CSF viscosity and tumor hemorrhage. ${ }^{34,39}$ Rostral extension of syringomyelia to the cervicomedullary junction can also cause hydrocephalus by mechanical obstruction of CSF outlet pathways in low-grade intramedullary tumors. The presence of syringomyelia in patients with low-grade tumors such as ependymomas and hemangioblastomas was not found to be associated with long-term disease outcomes. ${ }^{41}$ Similarly, shunt placement was indirectly found to be negatively correlated with survival due to an association with high-grade lesions. ${ }^{4}$

Importantly, hydrocephalus may precede or accompany development of neurological symptoms secondary to the underlying tumor and may also develop postoperatively. It often occurs with delayed onset, thereby mandating long-term radiological follow-up. ${ }^{34}$ In our series, there was no significant association between tumor grade and incidence of secondary hydrocephalus and/or syringomyelia. We chose to categorize patients with secondary hydrocephalus and syringomyelia together for outcome analysis, since in our experience these conditions had a 


\section{R. Ahmed et al.}

TABLE 6: Factors associated with disease progression

\begin{tabular}{|c|c|c|c|c|c|}
\hline \multirow[b]{2}{*}{ Characteristic } & \multirow{2}{*}{$\begin{array}{c}\text { No } \\
\text { Progression (\%) }\end{array}$} & \multirow{2}{*}{$\begin{array}{l}\text { Progression } \\
(\%)\end{array}$} & \multirow[b]{2}{*}{ Univariate Analysis $p$ Value } & \multicolumn{2}{|c|}{ Multivariate Analysis } \\
\hline & & & & $\mathrm{HR}$ & $\mathrm{p}$ Value \\
\hline \multicolumn{6}{|l|}{ age in yrs } \\
\hline$<5(n=20)$ & $11(55)$ & $9(45)$ & 0.3007 & & \\
\hline $6-13(n=18)$ & $7(39)$ & $11(61)$ & & & \\
\hline $14-21(n=17)$ & $11(65)$ & $6(35)$ & & & \\
\hline \multicolumn{6}{|l|}{ sex } \\
\hline male $(n=30)$ & $16(53)$ & $14(47)$ & 0.9214 & & \\
\hline female $(n=25)$ & $13(52)$ & $12(48)$ & & & \\
\hline \multicolumn{6}{|l|}{ pathology } \\
\hline \multicolumn{6}{|l|}{ tumor histology } \\
\hline astrocytoma $(n=31)$ & $13(42)$ & $18(58)$ & 0.2979 & & \\
\hline ependymoma $(n=10)$ & $7(70)$ & $3(30)$ & & & \\
\hline ganglioglioma $(n=7)$ & $4(57)$ & $3(43)$ & & & \\
\hline other $(n=7)$ & $5(71)$ & $2(29)$ & & & \\
\hline \multicolumn{6}{|l|}{ grade } \\
\hline high $(n=43)$ & $5(42)$ & $7(58)$ & 0.3854 & & \\
\hline low $(n=12)$ & $24(56)$ & $19(44)$ & & & \\
\hline \multicolumn{6}{|l|}{$\begin{array}{l}\text { clinical presentation } \\
\text { deficit score }\end{array}$} \\
\hline$<2(\mathrm{n}=39)$ & $23(59)$ & $16(41)$ & 0.1474 & & \\
\hline$>2(n=16)$ & $6(38)$ & $10(63)$ & & & \\
\hline \multicolumn{6}{|l|}{ funct'l grade on presentation } \\
\hline$I-I I(n=37)$ & $23(62)$ & $14(38)$ & $0.0804^{*}$ & & \\
\hline III $(n=6)$ & $1(17)$ & $5(83)$ & & & \\
\hline IV-V (n= 12) & $5(42)$ & $7(58)$ & & & \\
\hline \multicolumn{6}{|l|}{ tumor location } \\
\hline cervical $(n=27)$ & $14(52)$ & $13(48)$ & 0.4227 & & \\
\hline thoracic $(n=23)$ & $11(48)$ & $12(52)$ & & & \\
\hline lumbar $(n=5)$ & $4(80)$ & $1(20)$ & & & \\
\hline \multicolumn{6}{|l|}{ myelotomy levels } \\
\hline cervical $(n=24)$ & $12(50)$ & $12(50)$ & 0.6453 & & \\
\hline thoracic $(n=27)$ & $14(52)$ & $13(48)$ & & & \\
\hline lumbar $(n=4)$ & $3(75)$ & $1(25)$ & & & \\
\hline \multicolumn{6}{|l|}{ syrinx } \\
\hline yes $(n=16)$ & $8(50)$ & $8(50)$ & 0.6471 & & \\
\hline no $(n=28)$ & $16(57)$ & $12(43)$ & & & \\
\hline \multicolumn{6}{|l|}{ margins } \\
\hline circumscribed $(n=15)$ & $6(50)$ & $6(50)$ & 0.7625 & & \\
\hline diffuse $(n=29)$ & $16(55)$ & $13(45)$ & & & \\
\hline \multicolumn{6}{|l|}{ enhancement } \\
\hline yes $(n=40)$ & $20(50)$ & $20(50)$ & $0.0555^{\star}$ & & \\
\hline no $(n=4)$ & $4(100)$ & $0(0)$ & & & \\
\hline \multicolumn{6}{|l|}{ tumor span } \\
\hline $1-2$ vertebral levels $(n=13)$ & $8(61)$ & $5(38)$ & 0.4497 & & \\
\hline $3-4$ vertebral levels $(n=18)$ & $10(56)$ & $8(44)$ & & & \\
\hline $5-6$ vertebral levels $(n=14)$ & $8(57)$ & $6(43)$ & & & \\
\hline$>7$ vertebral levels $(n=10)$ & $3(30)$ & $7(70)$ & & & \\
\hline
\end{tabular}

(continued) 
Long-term outcomes in pediatric intramedullary tumors

TABLE 6: Factors associated with disease progression (continued)

\begin{tabular}{|c|c|c|c|c|c|}
\hline \multirow[b]{2}{*}{ Characteristic } & \multirow{2}{*}{$\begin{array}{c}\text { No } \\
\text { Progression (\%) }\end{array}$} & \multirow{2}{*}{$\begin{array}{c}\text { Progression } \\
\text { (\%) }\end{array}$} & \multirow[b]{2}{*}{ Univariate Analysis $p$ Value } & \multicolumn{2}{|c|}{ Multivariate Analysis } \\
\hline & & & & $\mathrm{HR}$ & $p$ Value \\
\hline \multicolumn{6}{|l|}{ surgical treatment } \\
\hline \multicolumn{6}{|l|}{ extent of resection } \\
\hline $\operatorname{GTR}(n=21)$ & $16(76)$ & $5(24)$ & $0.0062^{*}$ & 0.06 & \\
\hline $\operatorname{STR}(n=34)$ & $13(38)$ & $21(62)$ & & & \\
\hline \multicolumn{6}{|l|}{ shunt placement } \\
\hline yes $(n=12)$ & $3(25)$ & $9(75)$ & $0.0296^{*}$ & & \\
\hline no $(n=43)$ & $26(60)$ & $17(40)$ & & & \\
\hline \multicolumn{6}{|l|}{ funct'l status on discharge } \\
\hline$|-| \mid(n=38)$ & $24(63)$ & $14(37)$ & 0.0603 & & \\
\hline III $(n=5)$ & $1(20)$ & $4(80)$ & & & \\
\hline$I V-V(n=12)$ & $4(33)$ & $8(67)$ & & & \\
\hline \multicolumn{6}{|l|}{$\begin{array}{l}\text { adjuvant treatment } \\
\text { chemo/RT used }\end{array}$} \\
\hline chemo \& RT $(n=10)$ & $2(20)$ & $8(80)$ & $0.0033^{*}$ & & \\
\hline $\mathrm{RT}(\mathrm{n}=16)$ & $2(31)$ & $11(69)$ & & & \\
\hline chemo $(n=6)$ & $4(67)$ & $2(33)$ & & & \\
\hline none $(n=23)$ & $18(78)$ & $5(22)$ & & & \\
\hline \multicolumn{6}{|l|}{ indication for chemo } \\
\hline not used $(n=39)$ & $23(59)$ & $16(41)$ & 0.2104 & & \\
\hline adjuvant or recurrence $(n=15)$ & $6(40)$ & $9(60)$ & & & \\
\hline \multicolumn{6}{|l|}{ indication for RT } \\
\hline not used $(n=27)$ & $20(74)$ & $7(26)$ & $0.0057^{*}$ & 0.22 & \\
\hline adjuvant or recurrence $(n=25)$ & $9(36)$ & $16(64)$ & & & \\
\hline \multicolumn{6}{|l|}{ no. of tumor surgeries } \\
\hline $1(n=39)$ & $26(67)$ & $13(33)$ & $0.0012^{*}$ & 8.7 & 0.01 \\
\hline$>1(n=16)$ & $3(19)$ & $13(81)$ & & & \\
\hline \multicolumn{6}{|l|}{ funct'l status on final follow-up } \\
\hline$|-| \mid(n=48)$ & $27(56)$ & $21(44)$ & 0.3819 & & \\
\hline III $(n=4)$ & $1(25)$ & $3(75)$ & & & \\
\hline IV-V $(n=3)$ & $1(33)$ & $2(67)$ & & & \\
\hline
\end{tabular}

* Factors included in multivariate analysis.

similar presentation, both required CSF diversion, and were both associated with a significant effect on longterm disease survival. In our opinion, the pathogenesis of secondary syringomyelia is a manifestation of obstruction of subarachnoid CSF drainage pathways within the spine-either due to local disease progression or as a consequence of tissue reparative mechanisms and scarring. This is supported by our clinical observations of neurological improvement following placement of syrinxsubarachnoid shunts.

\section{Additional Factors Associated With OS and PFS}

Age as Null Predictor. In our experience, age does not affect OS, disease progression, or the rate of functional improvement. This indicates that despite the potential morbidity associated with resection, surgery is well tolerated, and GTR, when safely feasible, should be the primary treatment goal. Hence, this mandates prompt tumor resection even in infants presenting with severe deficits. This is consistent with earlier studies., ${ }^{4,476}$

Number of Tumor Resections. Overall survival was significantly lower in patients who underwent more than 1 tumor resection procedure as compared with patients who had 1 resection only (50\% vs $82 \%$, respectively). This reflects the greater rate of disease progression in the former group (81\%) as compared with that of patients who had 1 resection (22\%; Table 6).

Tumor Characteristics. We did not find any prognostic significance for additional tumor characteristics, such as preoperative syrinx, tumor margins, contrast enhancement, or spinal level. Significantly, longitudinal tumor span was not associated with adverse survival outcomes, indicating that even extensive multisegment intramedullary tumors can be resected with minimal adverse impact on disease survival, consistent with earlier reports..$^{10,12,47}$ 


\section{R. Ahmed et al.}

Natural History and Long-Term Neurological Outcomes Following Surgery

Clinical Presentation. In our pediatric series, the most common location for tumor presentation was the cervicomedullary junction (36\%), followed by the thoracic spine $(27 \%)$. Astrocytomas $(53 \%)$ were the most prevalent histological subtype, consistent with earlier studies. ${ }^{3,4}$ Despite the pattern of contrast enhancement on MRI $(91 \%)$, most of these tumors were low grade $(78 \%) .{ }^{8} \mathrm{Al}-$ though the average time interval from symptom development to clinical presentation was 7 months, most patients (67\%) presented with McCormick Grade I-II functional status. This underscores previous observations that, unlike their intracranial counterparts, intramedullary lowgrade gliomas should be primarily managed surgically on discovery to avoid any further neurological deterioration.

Rate of Improvement. Sensory deficits $(76 \%)$ were the most prevalent type of neurological deficit on initial presentation, with motor symptoms $(60 \%)$ next in prevalence. Most patients experienced improvement in their preoperative neurological deficit following resection. The prevalence of postoperative improvements was $70 \%$ and $64 \%$ for initial motor and sensory deficits, respectively. Improvement in preoperative bowel $(40 \%)$ and bladder $(9 \%)$ deficits were much less consistent. Overall, $55 \%$ of the study group experienced neurological improvement by the last clinical follow-up visit. This is within the range of previously reported rates of neurological improvement. ${ }^{16,51}$ Importantly, our extended follow-up enables us to conclude that our reported rates of neurological improvement are well maintained beyond the 1st decade postoperatively. Stratification by functional grade on presentation indicated that the rate of neurological improvement was in the range of 55\%-63\% for patients presenting with Grades I-II functional status and $50 \%$ for patients presenting with more severe grades, IV-V. Preoperative functional status was the only significant predictor of postoperative neurological improvement in our series, consistent with earlier studies. ${ }^{23,42,50}$ Hence, we concur with Garcés-Ambrossi et al. ${ }^{16}$ that neurological restoration rather than preservation ${ }^{45}$ should be the treatment goal, especially in the pediatric age group.

Postoperative Neurological Decline. Despite widespread use of intraoperative neurophysiological monitoring, immediate postoperative neurological decline has been widely reported.,28,29 This has been attributed to operative manipulation of the dorsal columns during the surgical myelotomy and reactive tissue edema with temporary neuronal injury and may correlate with poorer preoperative neurological status. ${ }^{14,20}$ The incidence of new-onset neurological deficits and/or progression of preexisting deficits in the immediate postoperative period in our series was $27 \%$ (occurring in 15 of 55 cases). The majority of motor-related symptoms $(63 \%)$ were transient (median time to resolution 3 months). Sensory deficits resolved postoperatively in $50 \%$ of cases (median time to resolution 7 months). This is consistent with previous reports. ${ }^{19}$

\section{Role of Adjunct Therapy}

The role of both chemo- and radiotherapy is ambigu- ous in the literature, with reports of indeterminate, improved, and no survival advantages conferred by these adjuncts. . $^{2,22,26,32,33,36,44,46}$ The overall rate of tumor progression in our series was $47 \%$, with a mean onset of 3 years postoperatively (mean $[ \pm$ SEM] $3.3 \pm 1$ years, range 0.1-20 years). Radiotherapy was used following disease progression or recurrence in $51 \%$ of the 55 patients, while chemotherapy was used in $29 \%$ of the patients. The independent survival and/or treatment benefit of these adjunct therapies could not be determined for lack of randomization of treatment modalities inherent to retrospective reviews. In our study group, inclusion of adjuvant therapies did not significantly improve OS. Inclusion of radiotherapy was statistically associated with 5-year PFS and represents an intrinsic selection bias because patients receiving radiotherapy are at high risk of disease progression.

\section{Conclusions}

Assessments of long-term OS and disease progression in children with intramedullary tumors show that GTR and tumor grade are the most significant factors in survival. Moreover, the survival advantages conferred by GTR appear to sustain beyond the 1st decade after treatment. Gross-total resection was associated with improved PFS at 5 years. Kaplan-Meier analysis showed the rate of PFS to be $44 \%$ for as long as 2 decades postoperatively. Long-term follow-up also demonstrated prolonged OS, especially in patients in whom there was no sign of disease progression. Neurological improvement occurred in $55 \%$ of patients postoperatively and was sustained by surviving patients over long-term follow-up.

\section{Disclosure}

The authors report no conflict of interest concerning the materials or methods used in this study or the findings specified in this paper.

Author contributions to the study and manuscript preparation include the following. Conception and design: Menezes, Ahmed. Acquisition of data: Menezes, Ahmed, Awe. Analysis and interpretation of data: all authors. Drafting the article: all authors. Critically revising the article: all authors. Reviewed submitted version of manuscript: all authors. Approved the final version of the manuscript on behalf of all authors: Ahmed. Statistical analysis: Ahmed, Torner. Study supervision: Menezes.

\section{References}

1. Ahmed R, Menezes AH, Awe OO, Mahaney KB, Torner JC, Weinstein SL: Long-term incidence and risk factors for development of spinal deformity following resection of pediatric intramedullary spinal cord tumors. Clinical article. J Neurosurg Pediatr [epub ahead of print April 4, 2014. DOI: 10.3171/2014.1.PEDS13317]

2. Bouffet E, Pierre-Kahn A, Marchal JC, Jouvet A, Kalifa C, Choux M, et al: Prognostic factors in pediatric spinal cord astrocytoma. Cancer 83:2391-2399, 1998

3. Constantini S, Houten J, Miller DC, Freed D, Ozek MM, Rorke LB, et al: Intramedullary spinal cord tumors in children under the age of 3 years. J Neurosurg 85:1036-1043, 1996

4. Constantini S, Miller DC, Allen JC, Rorke LB, Freed D, Epstein FJ: Radical excision of intramedullary spinal cord tumors: surgical morbidity and long-term follow-up evaluation 
in 164 children and young adults. J Neurosurg 93 (2 Suppl): 183-193, 2000

5. Cooper PR: Outcome after operative treatment of intramedullary spinal cord tumors in adults: intermediate and long-term results in 51 patients. Neurosurgery 25:855-859, 1989

6. Cooper PR, Epstein F: Radical resection of intramedullary spinal cord tumors in adults. Recent experience in 29 patients. J Neurosurg 63:492-499, 1985

7. Cristante L, Herrmann HD: Surgical management of intramedullary spinal cord tumors: functional outcome and sources of morbidity. Neurosurgery 35:69-76, 1994

8. DeSousa AL, Kalsbeck JE, Mealey J Jr, Campbell RL, Hockey A: Intraspinal tumors in children. A review of 81 cases. J Neurosurg 51:437-445, 1979

9. Doireau V, Grill J, Zerah M, Lellouch-Tubiana A, Couanet D, Chastagner P, et al: Chemotherapy for unresectable and recurrent intramedullary glial tumours in children. Br J Cancer 81:835-840, 1999

10. Ebner FH, Roser F, Falk M, Hermann S, Honegger J, Tatagiba M: Management of intramedullary spinal cord lesions: interdependence of the longitudinal extension of the lesion and the functional outcome. Eur Spine J 19:665-669, 2010

11. Epstein F: Spinal cord astrocytomas of childhood. Adv Tech Stand Neurosurg 13:135-169, 1986

12. Epstein F, Epstein N: Surgical management of holocord intramedullary spinal cord astrocytomas in children. Report of three cases. J Neurosurg 54:829-832, 1981

13. Epstein FJ, Farmer JP, Freed D: Adult intramedullary astrocytomas of the spinal cord. J Neurosurg 77:355-359, 1992

14. Epstein FJ, Farmer JP, Freed D: Adult intramedullary spinal cord ependymomas: the result of surgery in 38 patients. J Neurosurg 79:204-209, 1993

15. Fornari M, Pluchino F, Solero CL, Giombini S, Luccarelli G, Oliveri G, et al: Microsurgical treatment of intramedullary spinal cord tumours. Acta Neurochir Suppl (Wien) 43:3-8, 1988

16. Garcés-Ambrossi GL, McGirt MJ, Mehta VA, Sciubba DM, Witham TF, Bydon A, et al: Factors associated with progression-free survival and long-term neurological outcome after resection of intramedullary spinal cord tumors: analysis of 101 consecutive cases. Clinical article. J Neurosurg Spine 11:591-599, 2009

17. Goh KY, Velasquez L, Epstein FJ: Pediatric intramedullary spinal cord tumors: is surgery alone enough? Pediatr Neurosurg 27:34-39, 1997

18. Guidetti B, Mercuri S, Vagnozzi R: Long-term results of the surgical treatment of 129 intramedullary spinal gliomas. J Neurosurg 54:323-330, 1981

19. Hanbali F, Fourney DR, Marmor E, Suki D, Rhines LD, Weinberg JS, et al: Spinal cord ependymoma: radical surgical resection and outcome. Neurosurgery 51:1162-1174, 2002

20. Innocenzi G, Raco A, Cantore G, Raimondi AJ: Intramedullary astrocytomas and ependymomas in the pediatric age group: a retrospective study. Childs Nerv Syst 12:776-780, 1996

21. Jallo GI, Kothbauer KF, Epstein FJ: Intrinsic spinal cord tumor resection. Neurosurgery 49:1124-1128, 2001

22. Kane PJ, el-Mahdy W, Singh A, Powell MP, Crockard HA: Spinal intradural tumours: Part II-Intramedullary. Br J Neurosurg 13:558-563, 1999

23. Karikari IO, Nimjee SM, Hodges TR, Cutrell E, Hughes BD, Powers CJ, et al: Impact of tumor histology on resectability and neurological outcome in primary intramedullary spinal cord tumors: a single-center experience with 102 patients. Neurosurgery 68:188-197, 2011

24. Kothbauer K, Deletis V, Epstein FJ: Intraoperative spinal cord monitoring for intramedullary surgery: an essential adjunct. Pediatr Neurosurg 26:247-254, 1997

25. Lonser RR, Weil RJ, Wanebo JE, DeVroom HL, Oldfield EH: Surgical management of spinal cord hemangioblastomas in patients with von Hippel-Lindau disease. J Neurosurg 98:106-116, 2003

26. Lowis SP, Pizer BL, Coakham H, Nelson RJ, Bouffet E: Chemotherapy for spinal cord astrocytoma: can natural history be modified? Childs Nerv Syst 14:317-321, 1998

27. Lunardi P, Licastro G, Missori P, Ferrante L, Fortuna A: Management of intramedullary tumours in children. Acta Neurochir (Wien) 120:59-65, 1993

28. Matsuyama Y, Sakai Y, Katayama Y, Imagama S, Ito Z, Wakao N, et al: Surgical results of intramedullary spinal cord tumor with spinal cord monitoring to guide extent of resection. Clinical article. J Neurosurg Spine 10:404-413, 2009

29. McCormick PC, Stein BM: Intramedullary tumors in adults. Neurosurg Clin N Am 1:609-630, 1990

30. McGirt MJ, Chaichana KL, Atiba A, Attenello F, Woodworth GF, Jallo GI: Neurological outcome after resection of intramedullary spinal cord tumors in children. Childs Nerv Syst 24:93-97, 2008

31. McGirt MJ, Chaichana KL, Atiba A, Attenello F, Yao KC, Jallo GI: Resection of intramedullary spinal cord tumors in children: assessment of long-term motor and sensory deficits. J Neurosurg Pediatr 1:63-67, 2008

32. Merchant TE, Kiehna EN, Thompson SJ, Heideman R, Sanford RA, Kun LE: Pediatric low-grade and ependymal spinal cord tumors. Pediatr Neurosurg 32:30-36, 2000

33. Minehan KJ, Shaw EG, Scheithauer BW, Davis DL, Onofrio BM: Spinal cord astrocytoma: pathological and treatment considerations. J Neurosurg 83:590-595, 1995

34. Mirone G, Cinalli G, Spennato P, Ruggiero C, Aliberti F: Hydrocephalus and spinal cord tumors: a review. Childs Nerv Syst 27:1741-1749, 2011

35. Morota N, Deletis V, Constantini S, Kofler M, Cohen H, Epstein FJ: The role of motor evoked potentials during surgery for intramedullary spinal cord tumors. Neurosurgery 41: 1327-1336, 1997

36. O’Sullivan C, Jenkin RD, Doherty MA, Hoffman HJ, Greenberg ML: Spinal cord tumors in children: long-term results of combined surgical and radiation treatment. J Neurosurg 81:507-512, 1994

37. Peraud A, Herms J, Schlegel J, Müller P, Kretzschmar H, Tonn JC: Recurrent spinal cord astrocytoma with intraventricular seeding. Childs Nerv Syst 20:114-118, 2004

38. Raco A, Esposito V, Lenzi J, Piccirilli M, Delfini R, Cantore G: Long-term follow-up of intramedullary spinal cord tumors: a series of 202 cases. Neurosurgery 56:972-981, 2005

39. Rifkinson-Mann S, Wisoff JH, Epstein F: The association of hydrocephalus with intramedullary spinal cord tumors: a series of 25 patients. Neurosurgery 27:749-754, 1990

40. Sala F, Palandri G, Basso E, Lanteri P, Deletis V, Faccioli F, et al: Motor evoked potential monitoring improves outcome after surgery for intramedullary spinal cord tumors: a historical control study. Neurosurgery 58:1129-1143, 2006

41. Samii M, Klekamp J: Surgical results of 100 intramedullary tumors in relation to accompanying syringomyelia. Neurosurgery 35:865-873, 1994

42. Sandalcioglu IE, Gasser T, Asgari S, Lazorisak A, Engelhorn T, Egelhof T, et al: Functional outcome after surgical treatment of intramedullary spinal cord tumors: experience with 78 patients. Spinal Cord 43:34-41, 2005

43. Sandler HM, Papadopoulos SM, Thornton AF Jr, Ross DA: Spinal cord astrocytomas: results of therapy. Neurosurgery 30:490-493, 1992

44. Scheinemann K, Bartels U, Huang A, Hawkins C, Kulkarni $\mathrm{AV}$, Bouffet E, et al: Survival and functional outcome of childhood spinal cord low-grade gliomas. Clinical article. J Neurosurg Pediatr 4:254-261, 2009

45. Schwartz TH, McCormick PC: Intramedullary ependymomas: clinical presentation, surgical treatment strategies and prognosis. J Neurooncol 47:211-218, 2000 


\section{R. Ahmed et al.}

46. Shrivastava RK, Epstein FJ, Perin NI, Post KD, Jallo GI: Intramedullary spinal cord tumors in patients older than 50 years of age: management and outcome analysis. J Neurosurg Spine 2:249-255, 2005

47. Tobias ME, McGirt MJ, Chaichana KL, Goldstein IM, Kothbauer KF, Epstein F, et al: Surgical management of long intramedullary spinal cord tumors. Childs Nerv Syst 24:219-223, 2008

48. Townsend N, Handler M, Fleitz J, Foreman N: Intramedullary spinal cord astrocytomas in children. Pediatr Blood Cancer 43:629-632, 2004

49. Vassilyadi M, Michaud J: Hydrocephalus as the initial presentation of a spinal cord astrocytoma associated with leptomeningeal spread. Pediatr Neurosurg 41:29-34, 2005

50. Woodworth GF, Chaichana KL, McGirt MJ, Sciubba DM, Jallo GI, Gokaslan Z, et al: Predictors of ambulatory function after surgical resection of intramedullary spinal cord tumors. Neurosurgery 61:99-106, 2007

51. Yang S, Yang X, Hong G: Surgical treatment of one hundred seventy-four intramedullary spinal cord tumors. Spine (Phila Pa 1976) 34:2705-2710, 2009

52. Zide BM, Wisoff JH, Epstein FJ: Closure of extensive and complicated laminectomy wounds. Operative technique. J Neurosurg 67:59-64, 1987

Manuscript submitted June 24, 2013.

Accepted January 27, 2014.

Portions of this work were presented in oral presentation format at the Annual Meeting of the American Association of Neurological Surgeons in 2012.

Please include this information when citing this paper: published online April 4, 2014; DOI: 10.3171/2014.1.PEDS13316.

Address correspondence to: Arnold H. Menezes, M.D., Department of Neurosurgery, University of Iowa Hospitals and Clinics, 200 Hawkins Dr., 1824 JPP, Iowa City, IA 52242. email: arnoldmenezes@uiowa.edu. 